\title{
Urbanization and climate change impacts on future urban flooding in Can Tho city, Vietnam
}

\author{
H. T. L. Huong ${ }^{1}$ and A. Pathirana ${ }^{2}$ \\ ${ }^{1}$ Vietnam Institute of Meteorology, Hydrology and Environment, Hanoi, Vietnam \\ ${ }^{2}$ UNESCO-IHE, Institute for Water Education, Westvest 7, Delft, The Netherlands
}

Correspondence to: A. Pathirana (a.pathirana@unesco-ihe.org)

Received: 12 October 2011 - Published in Hydrol. Earth Syst. Sci. Discuss.: 8 December 2011

Revised: 28 September 2012 - Accepted: 17 December 2012 - Published: 29 January 2013

\begin{abstract}
Urban development increases flood risk in cities due to local changes in hydrological and hydrometeorological conditions that increase flood hazard, as well as to urban concentrations that increase the vulnerability. The relationship between the increasing urban runoff and flooding due to increased imperviousness is better perceived than that between the cyclic impact of urban growth and the urban rainfall via microclimatic changes. The large-scale, global impacts due to climate variability and change could compound these risks. We present the case of a typical third world city - Can Tho (the biggest city in Mekong River Delta, Vietnam) - faced with multiple future challenges, namely: (i) the likely effect of climate change-driven sea level rise, (ii) an expected increase of river runoff due to climate change as estimated by the Vietnamese government, (iii) increased urban runoff driven by imperviousness, and (iv) enhancement of extreme rainfall due to urban growth-driven, microclimatic change (urban heat islands). A set of model simulations were used to construct future scenarios, combining these influences. Urban growth of the city was projected up to year 2100 based on historical growth patterns, using a land use simulation model (Dinamica EGO). A dynamic limited-area atmospheric model (WRF), coupled with a detailed land surface model with vegetation parameterization (Noah LSM), was employed in controlled numerical experiments to estimate the anticipated changes in extreme rainfall patterns due to urban heat island effect. Finally, a 1-D/2-D coupled urbandrainage/flooding model (SWMM-Brezo) was used to simulate storm-sewer surcharge and surface inundation to establish the increase in the flood hazard resulting from the changes. The results show that under the combined scenario of significant change in river level (due to climate-driven sea
\end{abstract}

level rise and increase of flow in the Mekong) and "business as usual" urbanization, the flooding of Can Tho could increase significantly. The worst case may occur if a sea level rise of $100 \mathrm{~cm}$ and the flow from upstream happen together with high-development scenarios. The relative contribution of causes of flooding are significantly different at various locations; therefore, detailed research on adaptation are necessary for future investments to be effective.

\section{Introduction}

In 2008, for the first time in the history of human civilization, more than half of the world's population was living in cities. By 2030 , the urban population will reach 5 billion $-60 \%$ of the world's population (UN, 2006). The increase in population in urban areas occurs more in developing countries than in developed countries. Many cities in the developing world are growing rapidly due to real population growth, but to a much larger extent due to migration from rural areas to the cities, and transformation of rural settlements into cities. The result is an uncontrolled urban sprawl with increasing human settlements, industrial growth and infrastructure development (UN, 2006).

Urbanization invariably increases the flood risk as a result of heightened vulnerability, stemming from population concentration, wealth, and infrastructure to smaller areas (Taisuke et al., 2009). Flood hazard also increases by hydrological and hydroclimatological changes brought about by the land use and microclimatic changes driven by urbanization (WMO/GWP, 2008). The hydrological changes that result in urban flooding are long understood and quantified. 
The increase in artificial surfaces due to urbanization causes an increase in flooding frequency due to poor infiltration and reduction of flow resistance (due to faster concentration times). The hydrometeorological changes driven by urbanization, and resulting impacts on extreme rainfall, are also being established: a significant amount of research over the last twenty years has shown a strong relationship between urban areas and local microclimate. The "urban heat island" (UHI) effect is now well established, whereby urban areas have higher temperatures than surrounding regions (Seto and Kaufmann, 2009). In many cases, UHI can increase the rainfall in the vicinity of the cities. A number of studies have found an increase in rainfall in regions downwind of urban areas, with increases as high as $25 \%$ in some cases (Shepherd et al., 2002; Mote et al., 2007).

In urbanized areas, huge amounts of anthropogenic waste heat is emitted due to human activities, and the increase of energy consumption is causing environmental problems, including temperature rise in the urban atmosphere (Aikawa et al., 2008). The absence of trees decreases the evapotranspiration and hence the latent heat flux. Further, the radiative properties of the urban environment are found to be distinctly different and to absorb more radiation due to the nature of the urban canopy. These changes in surface heat budget provide the atmospheric conditions over urbanized areas with some unique characteristics compared to those of pristine or rural areas (Shepherd et al., 2002; Pathirana et al., 2013). These changes can have significant impacts on the local circulation and meteorological parameters and their association with precipitation (Aikawa et al., 2008).

The climate variability and change have direct consequences on global flood hazard (Milly et al., 2008). The increased frequency of occurrence of flood events in the world is partially attributed to climate change-driven increase of extreme precipitation (IPCC, 2002, 2007). Due to global warming, the global water cycle is likely to be accelerated, resulting in many regions with increased flood magnitude, as well as flood frequency. Climate change is making weather less predictable, rains more uncertain and heavy storm rainfalls more likely. Heavy thunderstorms appear to have increased in frequency (ActionAid, 2006). The quantitative estimation of the impact of climate change on small-scale, extreme rainfall events is a developing research area and there is a large degree of uncertainty with the current estimates (IPCC, 2007).

Flood incidences in cities that are coastal or on river deltas are also influenced by climate change via the changes in sea level, tides and large-scale runoff changes (resulting in river level changes). The changes in sea level are fairly well established (IPCC, 2007). A global average sea level rise of $9-88 \mathrm{~cm}$ is expected over the next hundred years (UNFCCC, 2005). In Vietnam, sea level rose at the rate of about $3 \mathrm{~mm} \mathrm{yr}^{-1}$ during the period of 1993-2008 (MONRE, 2009a). Sea level rise increases the risk of coastal and delta floods, particularly in cases of storm surges.
The effective adaptation measures can be made only when the nature of the impact is well understood. For urban planning and disaster preparedness, the quantitative assessment of the increase of flood hazards is important. From a research point of view, this quantification is relatively simple regarding the impact of a single influencing variable (e.g. flood hazard increase due to increased imperviousness). However, such estimations are of little use for adaptation planning, for they do not represent the future reality adequately. On the other hand, the estimation of the combined impact of many of the important parameters is a challenging research problem that invariably results in higher degree of uncertainty and errors. Further, the results of such studies should essentially be treated only as indicators of a range of possibilities. However, such attempts are very much required for the adaptation planning to be realistic.

In this paper, we discuss the case of a typical third world city faced with all these future challenges, namely: (i) the effect of climate change driven sea level rise, (ii) likely increase of river runoff due to climate change, (iii) increase of urban runoff driven by imperviousness and (iv) enhancement of extreme rainfall due to urban growth-driven microclimatic change (urban heat islands).

Can Tho is a city of around 1.2 million population located on the south bank of the Hau River, the bigger branch of the Mekong River (see Sect. 2 for a detailed description). Its location on the bank of a large river (not more than $84 \mathrm{~km}$ upstream of the river mouth in South China Sea) and its low elevation (60-80 cm a.m.s.l. - above mean sea level), makes it vulnerable to all four of the above factors impacting flood hazard. The rapid increase of population/densities, poor living conditions, and poor quality of the infrastructure also cause the city's vulnerability to floods to increase.

In this study, model simulations have been used to estimate the changes in flood hazard in the city, driven by scenarios of future change that are both global (e.g. climate change) and local (urban growth). The climate change drivers have been studied widely and we used available research output to establish the magnitude of these (e.g. increase of river levels due to future sea level rise and increase of runoff upstream of Can Tho. All those studies have their own simplifications and uncertainties, which will invariably compound the uncertainty of the current analysis.). On the other hand, the impact of urbanization on local rainfall in Can Tho has not previously been studied. We use an urban growth model to predict the urbanization in the future, and then we employ controlled numerical experiments with an atmospheric-land surface model to estimate the impact of urbanization on local extreme precipitation by "what-if" type simulations of historical extreme rainfall events. Finally, a 1-D/2-D coupled urban drainage/flooding model (SWMM-Brezo) is used to simulate storm-sewer surcharge and surface inundation to establish the increase in flood risk resulting from the changes of rainfall and climate change drivers. This last analysis is 

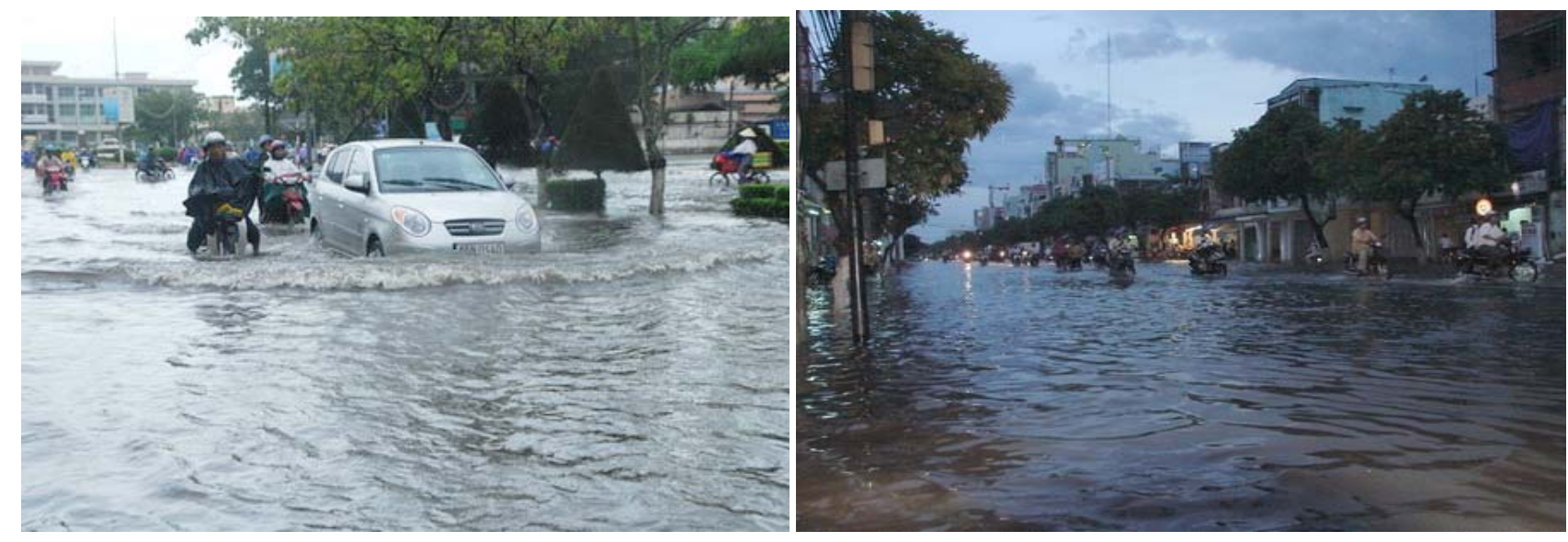

Fig. 1. Flooding in Can Tho City on 5 October 2009. Left panel: Hoa Binh Avenue.; right panel: whole Ly Tu Trong Street in the inner city was transformed into a river (Source: Youth online, 2009).

limited to a neighbourhood in the inner city due to limitations of data.

The results show that both local changes driven by urbanization and large-scale climate impact significantly influence the picture of the future flooding of Can Tho. The climate change-driven sea level and runoff increase cause the most serious increases to flood hazard in the city. In a worst case sea level rise up to $100 \mathrm{~cm}$, the surcharge from upstream and local hydrometeorological and hydrological changes caused by high development will increase the maximum inundation depth of an event similar to year 2009 flood by about $80 \%$.

There are two main causes for inundation that are represented by two classes of inundated areas: (i) along the canals, where the most serious inundation is largely caused by high water surcharge from the river, and (ii) areas in the center of the district that have been affected only by rainfall change and have not had clear impacts by the water surcharge from the river. These two different types of inundation call for different mitigatory action. We recommend that planning for response should follow careful study of the effectiveness of the different intervention options on each locality of the city.

The following sections describe the study area in detail with an overview of the flooding problem, followed by the research methodology adapted. Then we present the results, discussion and conclusions.

\section{Study area}

Can Tho city is the largest city of the Vietnamese Mekong River Delta and considered the capital of the region. In 2009, the city was recognized as a first level city (i.e., a city that is directly under central government's jurisdiction as compared to those of the provinces, which is the case for second level cities) in Vietnam and hence in the future, Can Tho is envisaged to develop considerably (NIURP, 2010). Over the next $20 \mathrm{yr}$, Can Tho is envisioned to be a dynamic city in the
Mekong River Delta Region, the southern part of Vietnam, and the adjacent international regions.

The area of the city is $1390 \mathrm{~km}^{2}$ with a population of 1.2 million (in April 2009). The city's population is projected to grow at a moderate rate, however, the inward migration towards the urban areas and industrial zones could possibly increase the total population to 1.8 million by 2020 (NIURP, 2010).

\subsection{Flooding problem in Can Tho}

Just like other cities in Vietnam, Can Tho faces many typical problems of urbanization (e.g. pollution, social issues), but one of the most serious problems is flooding. Recently, flooding in the city has happened more often and more seriously. It has been reported that in the past, the flooding area generally accounted for about $30 \%$ of the total city area, but recently that number has increased up to $50 \%$ (Tran Van Tu, 2010). In most cases the cause of flooding is a combination of factors. Severe floods occur when extreme rainfall coincides with high river level due to tide and upstream flow. Additionally, poor land use practices like building in flood-prone areas has contributed to this increase. Inundation happens even when the local rainfall is not too heavy. There are several historical flooding events recorded in the city, some of which are discussed below.

In 2000, heavy rainfall happened earlier than usual in the rainy season and caused serious flooding in the lower Mekong River Delta (National Hydro-meteorological Service, 2010a). This event was regarded as one of the biggest floods in the Mekong river Delta in recent history. The observed flooding at Tan Chau and Chau Doc were the highest recorded in last 76 yr. At Can Tho, flood levels were just 1$3 \mathrm{~cm}$ below the $40 \mathrm{yr}$ record level. The observed river level at Can Tho hydrological station was $1.9 \mathrm{~m}$ (National Hydrometeorological Service, 2010b). According to Can Tho Water Supply Company, in 2008, out of 81 main roads in the 
Table 1. Anticipated sea level rise $(\mathrm{cm})$ by the Vietnamese Government relative to the period 1980-1999.

\begin{tabular}{lcccccccccc}
\hline Scenarios & \multicolumn{1}{c}{ Decades in the 21st century } \\
\cline { 2 - 9 } & 2020 & 2030 & 2040 & 2050 & 2060 & 2070 & 2080 & 2090 & 2100 \\
\hline Low emission scenario (B1) & 11 & 17 & 23 & 28 & 35 & 42 & 50 & 57 & 65 \\
Medium emission scenario (B2) & 12 & 17 & 23 & 30 & 37 & 46 & 54 & 64 & 75 \\
High emission scenario (A1FI) & 12 & 17 & 24 & 33 & 44 & 57 & 71 & 86 & 100 \\
\hline
\end{tabular}

Source: Ministry of Natural Resources and Environment, Vietnam (MONRE, 2009b).

centre of the city, 21 were inundated with more than $30 \mathrm{~cm}$ water level, largely due to high tide, and 10 due to heavy rainfall (MONRE, 2009b). On 5 October 2009, heavy rains lasted over one hour and again caused serious inundation to the city. Several roads such as Mau Than, Tran Hung Dao, Xo Viet NgheTinh, HoaBinh, and Ly TuTrong were inundated under one-meter-high water. The residents said that this was the largest flood over several decades. Many houses and streets in the city were inundated (Fig. 1).

\subsection{Reasons for flooding today}

One reason for flooding in Can Tho is the low topography of the city, with the average height above mean sea level, ranging from 1 to $1.5 \mathrm{~m}$. In fact, many places have topography below $1 \mathrm{~m}$ a.m.s.l. and the ability to drain into the river remains limited. The average rainfall in the city is not significantly large $\left(1640 \mathrm{~mm} \mathrm{yr}^{-1}\right)$ compared to Vietnamese norms, but is prone to be concentrated in extreme events. Rainfall ranging from 50 to $100 \mathrm{~mm} \mathrm{day}^{-1}$, combined with high tide, typically causes flooding in Can Tho. Also, the city's drainage system is incomplete, and where it exists, is insufficiently dimensioned. The awareness of the people remains limited, which is also an indirect reason for more serious flooding: often people throw garbage into canals and drainage pipes and construct buildings encroaching canals. The inner city has grown significantly over the last several decades with more houses, businesses and factories being built.

A storm sewer network has been developed only for the central Ninh Kieu district (Fig. 2), and its capacity is inadequate during heavy rainfall. Urban flood protection is a matter under the control of Can Tho's municipal authorities. According to a survey by a construction consultant company (under the Ministry of Construction), the current drainage system of Can Tho has a total length of over $23500 \mathrm{~m}$ with the diameter ranging from 300 to $1200 \mathrm{~mm}$, and man-made ditches with a total length of over $7000 \mathrm{~m}$ (width ranging from 0.2 to $0.5 \mathrm{~m}$ ) and hundreds of meters of natural drainage ditches and canals. However, much of this drainage system is malfunctioning or has limited drainage capacity. At many places such as Mau Than Road, 30-4 Road, and 3-2 Road, the drainage system is encroached by illegal constructions or filled by solid waste. While in many other roads, the drainage system fails to meet the technical requirements, leading to limited capacity to collect waste-water or rainwater. The uncollected rainwater and gray water from sewer surcharges run over streets. When the surcharges coincide with high tide in Hau River, the city is seriously flooded.

Canals crisscrossing the city play an important role, acting as outlets for drainage network. Private houses are routinely constructed, obstructing these drainage canals and worsening the drainage capacity of the system. Funds for periodic dredging the canal bed are limited, so sedimentation also is a serious issue. In case of heavy rainfall combined with high tide, the water level in the canals often rise higher than that in the drainage pipes, causing surcharge and backflow. This is the prime reason for inundation in quarters close to the river or canals.

\subsection{Anticipated situation in the future}

The drainage system in Can Tho city is far from optimal and the flooding is already a problem. However, future changes will further aggravate this situation.

- Climate change: it is possible that climate change (CC) has already caused increase of frequency and magnitude in catastrophic natural disaster, especially typhoons, floods and droughts (MONRE, 2009a; Delgado et al., 2010). By the end of the 21 st century, the temperature in Vietnam may increase by $2.3^{\circ} \mathrm{C}$.

According to MONRE (2009a), relative to the average of 1980-1999, the annual and rainy season's rainfall is anticipated to increase by about $5 \%$ compared to that of the period 1980-1999, and the mean sea level is expected to increase about $30 \mathrm{~cm}$ by mid $21 \mathrm{st}$ century and $100 \mathrm{~cm}$ by the end of 21st century (MONRE, 2009a) (Table 1). ${ }^{1}$

- Urbanization effect: urbanization may likely cause increased precipitation, and therefore will cause more serious flooding for the city. Furthermore, the hydrological changes of urbanization will increase the flood peaks and decrease the concentration times.

\footnotetext{
${ }^{1}$ There is a very high degree of uncertainty with these estimates. For example, different global circulation models give very different results for the region, as e.g. Kingston et al. (2011) have shown in terms of flow projections for the Mekong.
} 


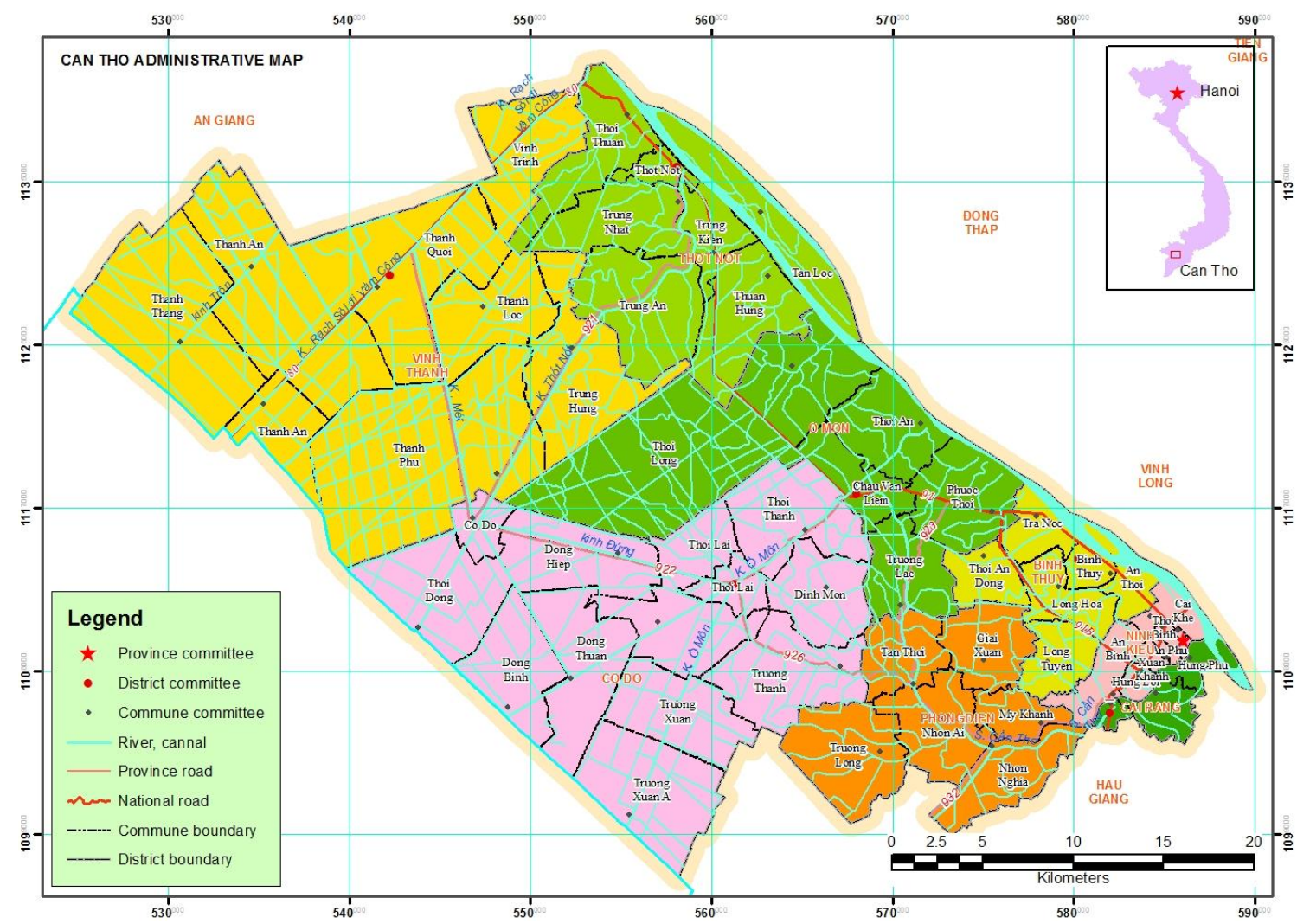

Fig. 2. A map of Can Tho city administrative area (includes the surrounding agricultural land).

With the strategic location of Can Tho city and the significant increase of population in the Mekong Delta in general, and urban population in Ho Chi Minh city (as a biggest urban and industrial conglomerate) in particular, there will be a significant increase in "climate induced" migrants into Can Tho. This factor could significantly increase the city's flood risk by an increase in vulnerability due to higher density and higher potential losses and damages from flood.

- Land Subsidence: land subsidence would also contribute to the increasing flooding situation in Can Tho city (Vietbao, 2006). However, there are no studies on the land subsidence rate in Can Tho.

It is anticipated that Can Tho city will witness an exponential growth during the next several decades, largely due to its strategic location. The dramatic change in land use within and surrounding the city will impose both direct (hydrological) and indirect (UHI) impacts on the urban water cycle, resulting in more frequent and higher-magnitude floods. The climate change-driven increase in sea level rise as well as potential increase of runoff of Mekong River could aggravate the problem.

Urgent adaptation actions are necessary to mitigate damage caused by floods in future in Can Tho. In order to develop sound adaptive measures, it is necessary to quantitatively estimate the impacts of the future changes on flooding with models for simulating the possible microclimatic changes, taken together with other signals of climate change (e.g. rainfall increase due to global warming, and sea level rise).

\section{Methodology}

We used three different simulation models to achieve the objectives of this study. The overall modeling framework is given in Fig. 3.

The main emphasis of the research will be on the impacts of global and local climate change on urban flooding. Whenever suitable external resources for impacts are available, they were directly adopted (e.g. global climate change impacts on extreme rainfall) with necessary caveats (e.g. scale issues).

However, for local changes (e.g. UHI), external resources are hardly available. The availability of good urban growth scenarios was fundamental for the study. In order to predict future urban growth scenarios, the cellular automatabased land use simulation model, Dinamica EGO (Mas et al., 2010), was used. The detailed procedure of modeling urban growth and its impacts are described by Pathirana et al. (2013). Output from Dinamica EGO was used as input 


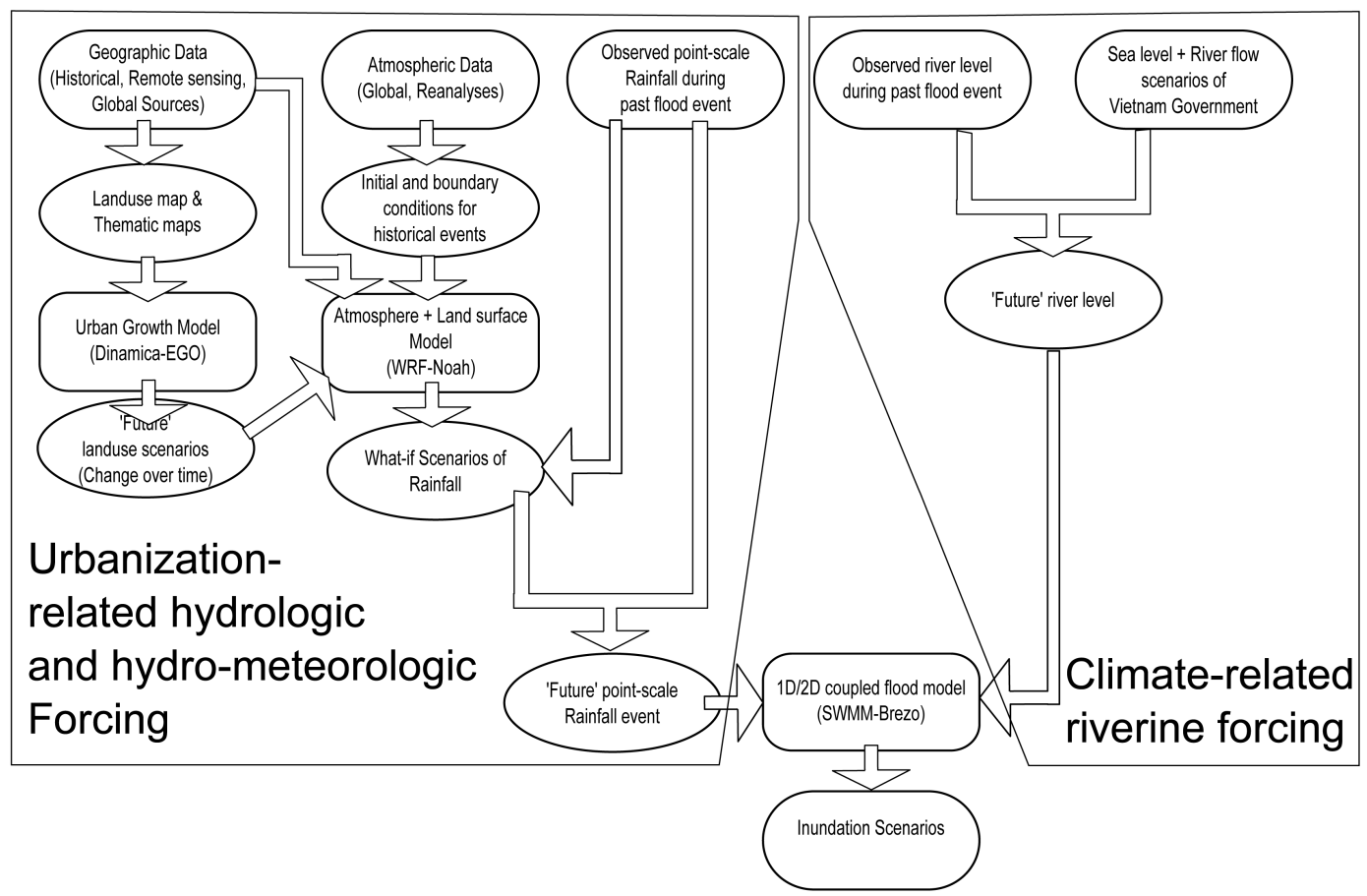

Fig. 3. The modeling framework used to quantify future changes in flooding. The climate change scenarios were adapted from outside sources.

in a specially modified mesoscale atmospheric model (Pathirana et al., 2013) to ascertain the changes that increased urbanization will induce in the urban microclimate for the city of Can Tho, resulting in changes in the precipitation patterns. To achieve this, a mesoscale atmospheric model (WRF), coupled with a land use model with vegetation parameterization (Noah LSM), was applied. The necessary modeling framework was already developed for this purpose (Pathirana et al., 2013; Verbeek et al., 2011), so this framework was applied for Can Tho city with the realistic urban growth scenarios. For urban flood modeling, an integrated seweragesurface flow model (SWMM-Brezo) developed during the period 2007-2010 was used (Delelegn et al., 2011).

\subsection{The models}

\subsubsection{The urban growth model}

Dinamica EGO is a spatially explicit cellular automata-based simulation model of landscape dynamics (Mas et al., 2010). EGO stands for Environment for Geo-processing Objects. In the current application, the basic task of the Dinamica EGO is to: (i) analyse historical urbanization patterns of Can Tho city, and (ii) use the historical transition patterns together with any other rules (e.g., areas that are protected from urbanization) to simulate the future land use change (Veerbek et al., 2011).

\subsubsection{The atmospheric model}

The Weather Research and Forecasting (WRF) is a nonhydrostatic, limited-area atmospheric model that can simulate the full set of atmospheric processes including wind, moisture-state-transformation (including cloud formation and precipitation) and destiny of atmospheric pollutants. It can be used to simulate situations ranging from simpleidealized numerical experiments to sophisticated real-time weather forecasting applications. The model requires the specification of initial conditions for the entire modeling domain and the lateral boundary conditions for the whole period of the model integration. Surface representation based on topography and land use could be a simple thermal diffusion model or a detailed land surface model with extensive surface and vegetation hydrology (Tewari et al., 2008). In the current application we used WRF coupled with Noah land surface model (Noah LSM) (Mitchell, 2005).

\subsubsection{The urban flood model}

In the case of design problems that involve prevention of flooding at a given design standard (rainfall event), often 1-D urban drainage models are adequate tools. However, the current application requires the simulation of surcharged conditions of storm sewers and estimation of inundation depth. Due to the highly dynamic and swift nature of urban floods, such estimations are best made by dynamic inundation models. In this study, a coupled 1-D/2-D model - a product of 


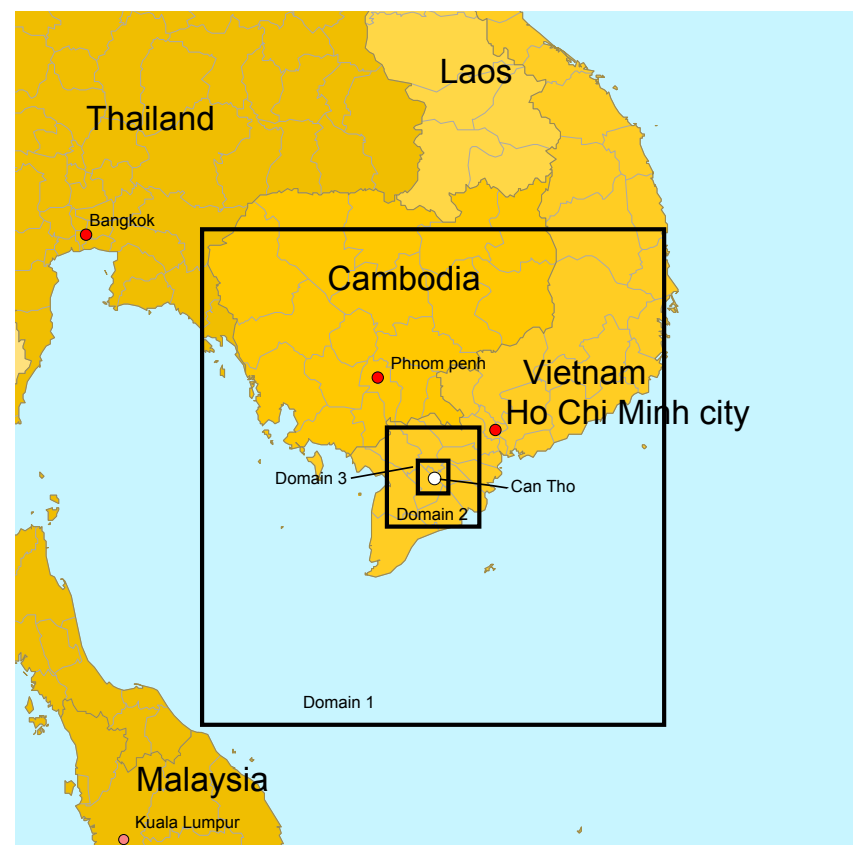

Fig. 4. The Can Tho WRF-Noah simulation setup. Three telescopic domains were used to achieve high-resolution simulations over Can Tho area.

coupling EPA-SWMM 5 (EPA, 2010) with Brezo (a 2-D inundation model; Begnudelli and Sanders, 2006) - was used for the purpose. The details of the coupled model are explained by Pathirana et al. (2011). The model is capable of dealing with various flow conditions that may occur in actual floodplains.

\subsection{Model application for Can Tho}

\subsubsection{Future land use}

Dinamica EGO needs at least two historical land use maps, ideally well spaced in time (so that there is a significant level of land use change occurring from first to the second), in order to calculate the past land use transition patterns of a specific city. For this study, we used Landsat data to derive land use maps for the years 1989 and 2005. Two land cover maps at $30 \mathrm{~m}$ spatial resolution for two different years were processed. The various land cover classes are then derived from these remotely sensed satellite images by maximum likelihood classification (supervised). For Can Tho, the following categories are identified from the training of RS images: open water; developed areas: low-intensity, medium-intensity and high-intensity; infrastructure; shrub and grassland. Land use simulation was done from 1989 to 2100 at time steps of $5 \mathrm{yr}$.

The resulting urban extent and land cover distribution predictions of the Can Tho city are used as input for the atmospheric model for further analysis of increases in precipitation and increment imperviousness to investigate the associ-

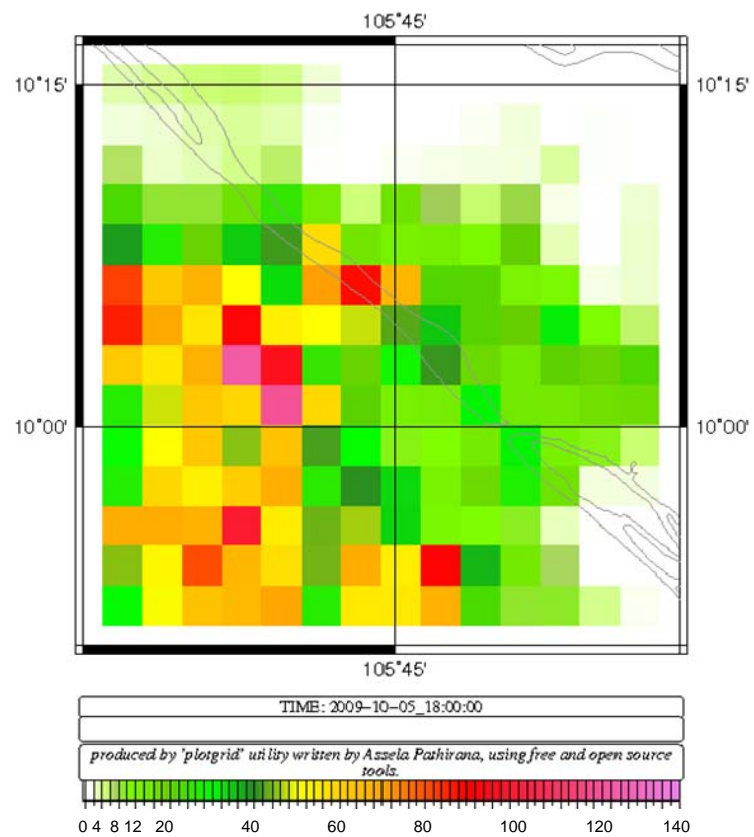

Fig. 5. WRF results (total accumulated rainfall in $\mathrm{mm}$ ) of 2009 October rainfall event over the six hour period from 12:00 to 18:00 of 5 th of October. Can Tho station recorded $80 \mathrm{~mm}$ of precipitation during the same period.

ated flood hazard. The process is explained in the sections below.

\subsubsection{Rainfall changes due to urbanization}

The application of the WRF-Noah coupled land surfaceatmospheric model was used to conduct sensitivity experiments of local rainfall to the changes in the urban microclimate by land use change. In order to do this effectively, it is necessary to cover the city and the surrounding region with relatively high spatial resolution. The domain configuration was set up to cover the study area with a resolution of $1 \mathrm{~km}$ (Fig. 4). However, the boundary condition data needed to run this model originates from much coarser global data sources (we used the product known as the NCEP FNL Operational Model Global Tropospheric Analyses, which comes in $1.0^{\circ} \times 1.0^{\circ}$ resolution.). The model domain needs to be rather large to use these boundary conditions and to allow for the atmospheric phenomena to be developed within the domain. The practical way of satisfying both these requirements with computational economy is to setup the model in a telescopic grid system. We set three-level two-way nesting domains. The time for integration step was $15 \mathrm{~s}$. The results of the historical rainfall event of October 2009 simulation are shown in Fig. 5.

The standard input of geographical data for WRF-Noah model is the USGS data sources. Then the configured model was used to estimate the change of rainfall due to 


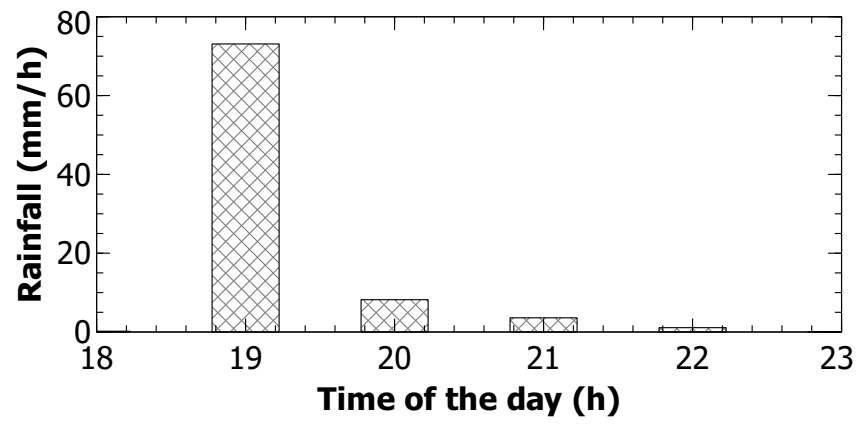

Fig. 6. Rainfall at Can Tho meteorological station (18 October 2000).

urbanization in the future by replacing the land use of the model with urban growth model-based values. This process is explained in the Results section.

\subsubsection{SWMM - Brezo}

The study area focuses on Ninh Kieu district (Can Tho city). Ninh Kieu is the central district of Can Tho city, enclosed by the Hau Giang and Can Tho rivers. The total area of the district is about 2900 ha. However, the sewer system only covers one part of the district (660 ha) to which we applied the urban inundation model.

The data for the 1-D/2-D coupled model were collected from three sources: (i) point-scale rainfall observations were collected from National Hydro-meteorological Service; (ii) detailed engineering drawings of the drainage system were collected from Can Tho Water Supply Company; (iii) Digital Elevation Model (DEM) was developed by the Vietnam Institute of Meteorology, Hydrology and Environment. Terrain property of objects in schematic outline was determined on DEM with resolution $15 \mathrm{~m} \times 15 \mathrm{~m}^{2}$. The elevation data was produced by digitizing topographic maps, obtained from the Department of Geodesy and Cartography, Ministry of Natural Resources and Environment, Vietnam.

The main parameters to be tuned in the hydraulic model were the roughness values for the conduit (1-D) flow and overland-inundation (2-D) flow. With all pipe material being concrete we used the value of 0.014 for the Manning's roughness of conduits. Typical value for smooth concrete pipes is lesser than this $(0.01)$, but we chose a higher value to somewhat compensate for the increased roughness due to blockages resulting from poor maintenance of the system. For urban inundation we used 0.3. This is a much higher than the standard values given for different urban material (e.g. gravel 0.03). However, it should be understood that due to the coarse nature of the grid representation, a significant degree of im-

\footnotetext{
${ }^{2}$ It should be noted that while the spatial resolution of the data was $15 \mathrm{~m} \times 15 \mathrm{~m}$, the vertical precision of the data was rather poor and probably suitable for a dataset of much coarser spatial resolution
}

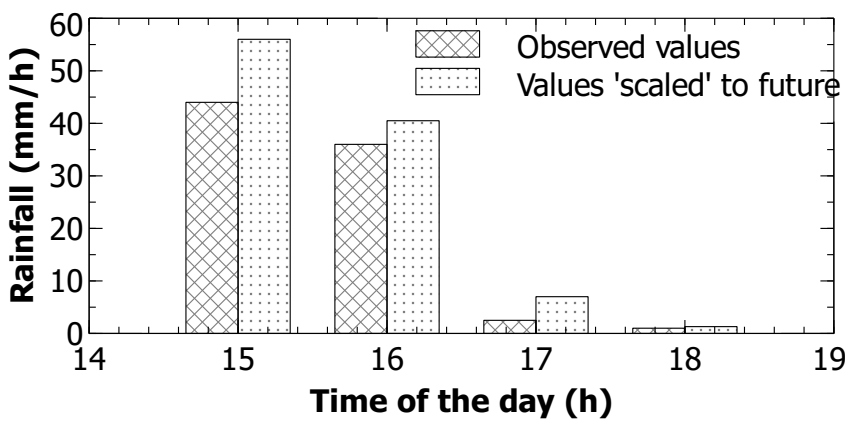

Fig. 7. Hourly rainfall at Can Tho meteorological station (5 October 2009). The anticipated hourly rainfall amounts in 2050 are also shown if the same event happened.

plicit smoothing has happened. The high Manning's roughness value compensates this. There was no data for a formal calibration and validation of the model. We simulated the flood events of year 2000 and 2009 (pluvial floods exacerbated by high river levels) to test the operation of the model. In 2000 and 2009, the heavy rainfall caused inundation in the city. The rainfall hyetographs for these events as recorded by Can Tho meteorological station are given in Figs. 6 and 7. The river water level hydrographs recorded by Can Tho station are shown in Fig. 8. In the 2000 event, the water level fluctuated (due to tidal effect) between +1.6 and +0.92 ; and in the 2009 event, between +1.69 and +0.28 . There were no records on the inundation depths in the city, except maximum observed flood level at Pham Ngu Lao Street $(0.8 \mathrm{~m})$ during the 2009 event. The value produced by our model was $0.84 \mathrm{~m}$. Apart from this, no formal validation of the model could be done due to lack of observed data.

Due to the flat nature of the land and the fact that the city is crisscrossed with canals, the drainage system has evolved into a fairly complex one. The 1-D SWMM urban model we built consists of 303 subcatchments, 524 conduits, 465 junctions, 51 outfalls and 8 pumps (Fig. 9). The 2-D Brezo model covered only the acutely flooded area (northwestern part of the 1-D network) of the city (Fig. 10). The 2-D model has 1.7 million triangular cells each of area $112.5 \mathrm{~m}^{2}$. The 1 D/2-D systems were bi-directionally, coupled using internal boundary conditions at each junction of the 1-D model.

\subsubsection{Climate change scenarios}

At present, many regions and countries have developed climate change scenarios at national, regional, or smaller scales. Most climate change scenarios are constructed for the time frame of decades of the 21st century.

In Vietnam there are also a number of climate change scenarios developed and applied for different purposes of climate change-related activities. In order to have more comprehensively scientific- and practical-based scenarios for the implementation of the National Target Program to Respond 


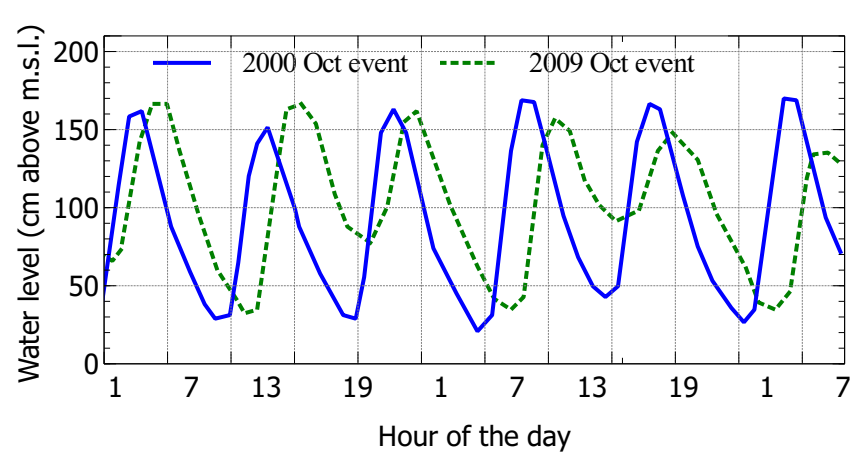

Fig. 8. Water level at Can Tho hydrological station (18 October 2000 and 5 October 2009).

to Climate change (NTP), the Ministry of Natural Resources and Environment (MONRE) was appointed by the government as the coordinating agency for developing climate change scenarios, especially sea level rise for Vietnam.

In November 2010, MONRE produced a report entitled "Impacts of Climate Change on Water Resources and Adaptation Measures" (hereafter referred to as the IMHEN report) as the final product of the project with the same name, sponsored by the Government of Denmark and participated in by consulting experts from the Danish Hydraulic Institute (DHI) and many agencies in Vietnam. We used the information in this report, together with clarifications obtained from the experts involved in the project, as boundary condition of the current study. It is necessary to point out that a number of simplifying assumptions have been made in the IMHEN (2010) report. These simplifications and shortcomings affect the results presented in this paper.

The sea level rise and river flow projections in the IMHEN (2010) report are based on a number of assumptions and simplifications. They used ECHAM4 GCM simulations, downscaled using the PRECIS regional climate model from Hadley Centre, UK, for contributing areas outside of Vietnam (e.g. upstream Mekong) and MAGICC/SCENGEN with statistical downscaling for regions within Vietnam. They use the SWAT model for upstream hydrology in the Mekong and hydrodynamic river model (ISIS model of Halcrow) to simulate the river level of Hau River with the combined effect of sea level rise and increase of flow in Mekong. However, due to the inherent limitations of the statistical downscaling methods used in the study, it was only possible to obtain mean monthly variations of rainfall over the Mekong - the changes in extreme rainfall cannot be seen. The changes in monthly rainfall are assumed to be a proxy for changes in extreme rainfall in the Mekong. Under these simplifications the mean river level around Can Tho is projected to increase by around $1.1 \mathrm{~m}$ by year 2100 as the combined result of increased river discharge and sea level rise (IMHEN, personal communications, 2010). This value has a very high degree of uncertainty.

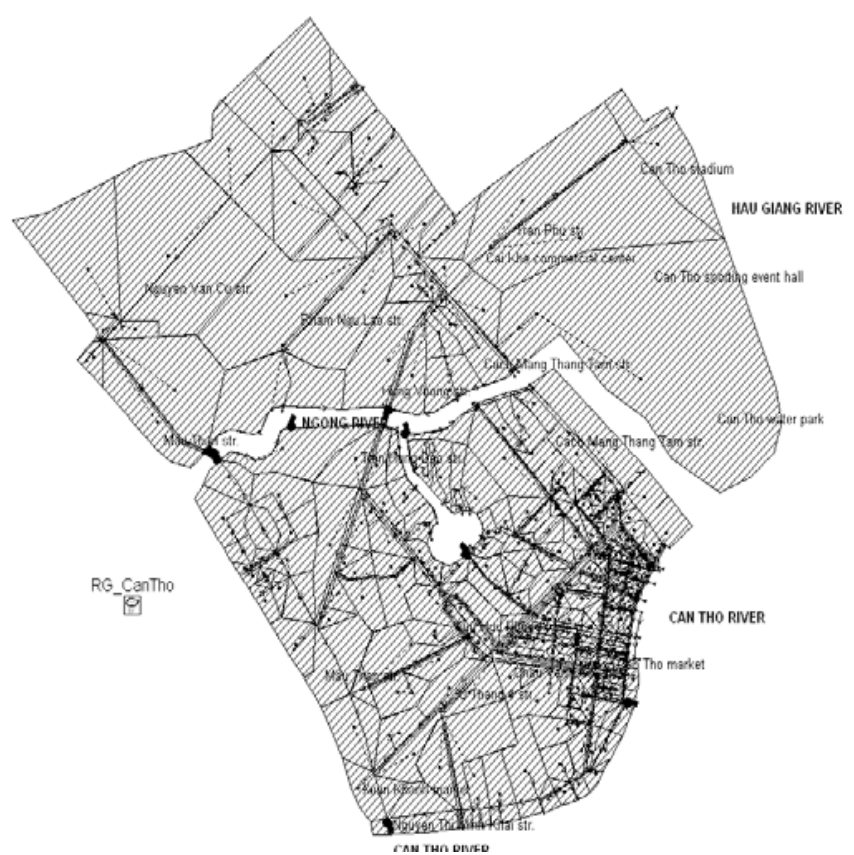

Fig. 9. 1-D SWMM model developed for Ninh Kieu District.

Due to the high uncertainty in the climate forcing on the riverine system, we limit the interpretation of the results to "what-if" types of scenarios without attaching a time span for the scenario to happen. For example we discuss $50 \mathrm{~cm}$ and $100 \mathrm{~cm}$ rise of the sea level, but do not fix a timescale for these to happen.

\section{Model application}

\subsection{Future urbanization}

We used the following method to develop the urbanization scenarios for the Can Tho city: the Dinamica EGO model was used to obtain historical transition rates from observed land use transition from 1989 to 2005 . These transition rates were then attributed by the model to various thematic datasets (e.g. road network, water bodies, elevation and slope) so that the model could "learn" how historical land use transition happened in Can Tho. Then under a "business as usual" (same relationships hold true for the future) assumption, this knowledge was extrapolated together with known planning-related information (e.g. restricted areas) to make projections of land cover maps for the years 2035, 2050 and 2100. While the implicit assumption that the transition patterns of the past hold true for the future, this does not imply a liner extrapolation of the growth rates. These, together with observed land cover in 2005, are shown in Fig. 11. We used the projection for 2050 as the "future" scenario for the study. The projection for 2100 was not used due to the even higher 


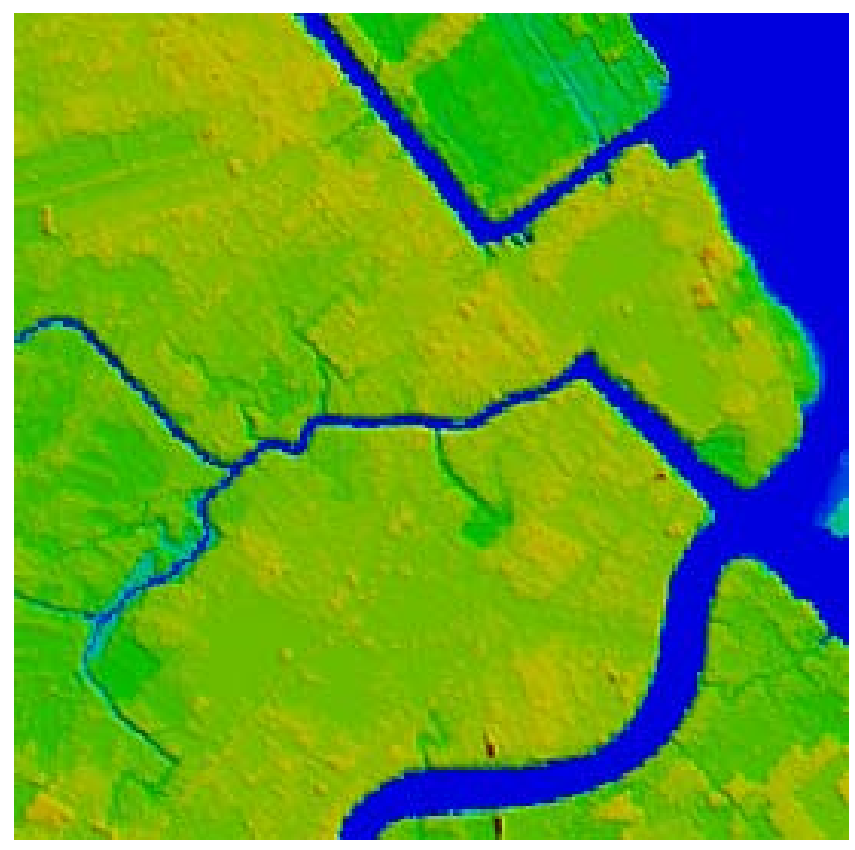

Fig. 10. The elevation map of the area covered in 2-D (Brezo) flood simulation.

level of uncertainty and due to the possibility that the growth patterns may change significantly over such a long period.

Comparison of the maps indicates that there could be a consistent infill and expansion of the current urban core in all the corners. Owing to the flat nature of the terrain, most of the land covered by grass and shrubs at the outskirts of the city is expected to be filled by scattered and low to medium intensity urbanization up to the mid-21st century. These would slowly change to a high-density metropolitan area by 2100 . There is also a considerable densification of the existing urban core at the heart of the city. A unique feature of urban growth of Can Tho is the high growth and densification along water bodies.

The total built-up area is expected to increase by $27.6 \mathrm{~km}^{2}$ by the year 2035, an approximate $41 \%$ increase in 30 years' time. By 2050, the total increment in built-up area with respect to the year 2005 is expected to be $38 \mathrm{~km}^{2}(55 \%)$. Grasslands and shrubs are subjected to a combined decrease of about $12 \%$ by 2035 and $17 \%$ by 2050 .

\subsection{Impacts of urbanization on local precipitation}

The land use distributions from the urban growth model were used as inputs for the atmospheric model runs to establish the impacts of urbanization on local precipitation. Two different maps of land use in the year of 2005 and 2050 were used to perform controlled numerical experiments to establish the possible changes of extreme rainfall if the city develops as in the projected scenario.
The process of obtaining these results is as follows: several historical storms over Can Tho city were selected. The WRF/Noah model has been developed by using NCEP-FNL global data as initial/boundary conditions and land use data from Dinamica EGO models (2005 as "Past" and 2050 as "Future"). The models were validated to closely reproduce the historical results with the "Past" scenario. The same model parameters were used with "Future" land use scenario in order to estimate the impact of urbanization on local precipitation. Figure 12 shows the differences between past and future simulated rainfall, in terms of total simulated rainfall amounts for the October 2009 event. Figure 13 shows the distribution of rainfall intensity quantiles at $15 \mathrm{~min}$ resolution for different historical events.

There is a clear impact of land use change due to urban growth on increasing the extreme rainfall quantities. In most of the cases, the results show that the rainfall may increase with the projected land use map of 2050 - especially for the heavy rainfalls of $30-40 \mathrm{~mm}$ in $15 \mathrm{~min}$. In the case of the historical rainfall event of 5 October 2009, the results show that, when precipitation more than $40 \mathrm{~mm}$, the rainfall in the " $\mathrm{Fu}$ ture" case is greater than in the "Past" case by about $10 \%$. These values were used for the urban flood simulation below.

\subsection{Impacts of urbanization and climate change on flooding}

In order to estimate the impacts of urbanization on the flooding situation for Can Tho city, results of the rainfall of October 2009 (in past and future land use maps) were used as input for all considered scenarios. For this event, "Future" rainfall series were constructed under the assumption that if the October 2009 event happened in 2050, its magnitude would increase by the indicated magnitudes of the respective statistical quantiles. An analysis similar to the one shown in Fig. 13 was done at an hourly level with all analysed rainfall events combined (in order get a more statistically robust estimate). Such an analysis gives a functional relationship between the quantiles of future and past rainfall:

$R_{\mathrm{F}}(Q)=f\left[R_{\mathrm{P}}(Q)\right]$,

where $R_{\mathrm{F}}(Q)$ and $R_{\mathrm{P}}(Q)$ are hourly rainfall intensities of the quantile $Q$ in the future and past, respectively. Then the "Future" event $r_{\mathrm{F}}(t)$ of a recorded extreme rainfall event $r_{\mathrm{P}}(t)$ was estimated as

$r_{\mathrm{F}}(t)=r_{\mathrm{P}}(t) \frac{f\left[R_{\mathrm{P}}(Q)\right]}{R_{\mathrm{P}}(Q)}$.

However, it should be noted that as shown in Fig. 11, the relationship between future and past rainfall varies from event to event. Therefore, the "scaling" provided by the above equation is average and will depend on the ensemble of rainfall events considered.

Results of eight different combinations of scenarios are discussed in this paper for four climate scenarios: (i) current situation, (ii) sea level rise of $50 \mathrm{~cm}$, (iii) sea level rise of 

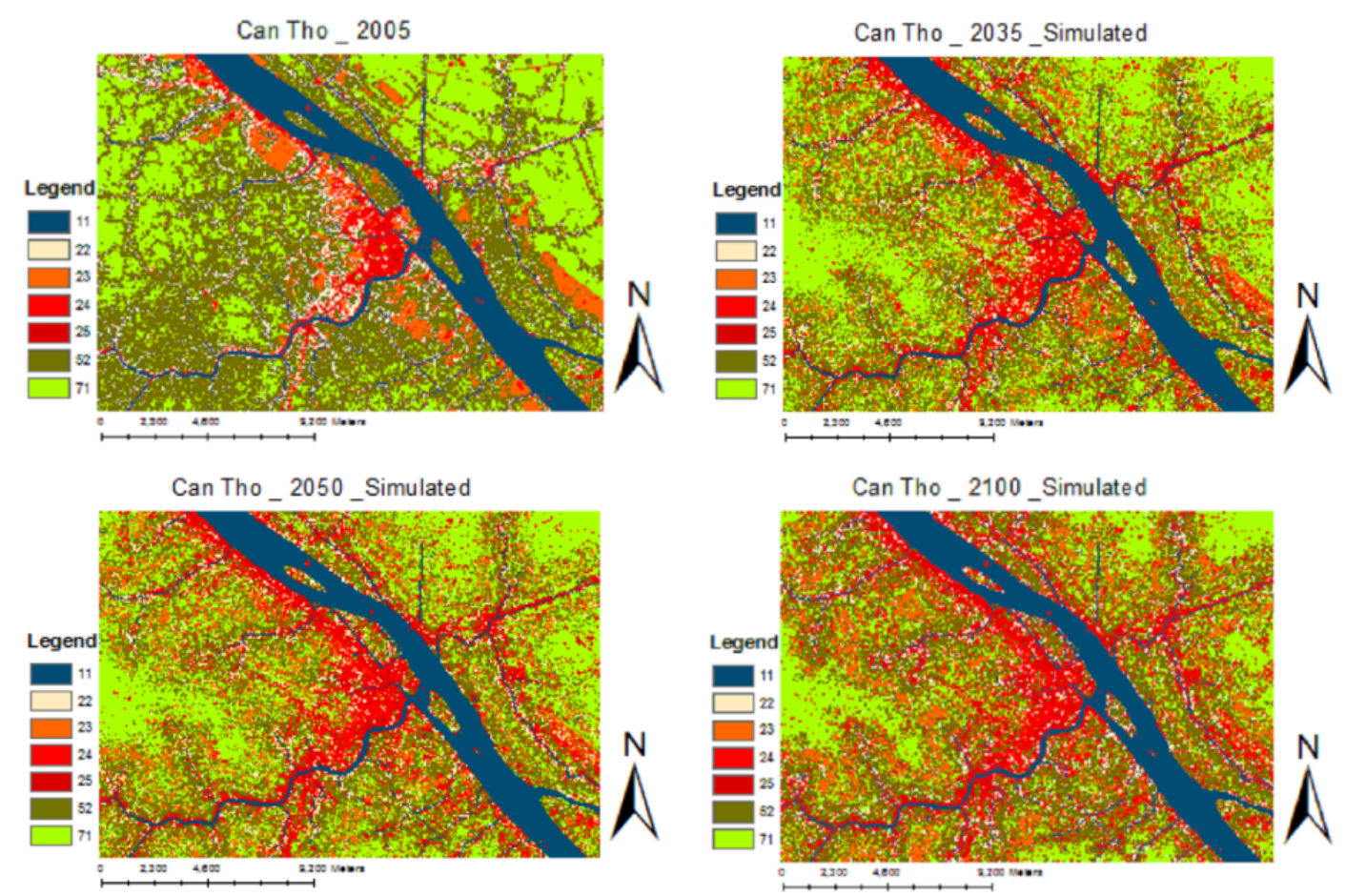

Fig. 11. Future land use change in Can Tho predicted by Dinamica EGO model.
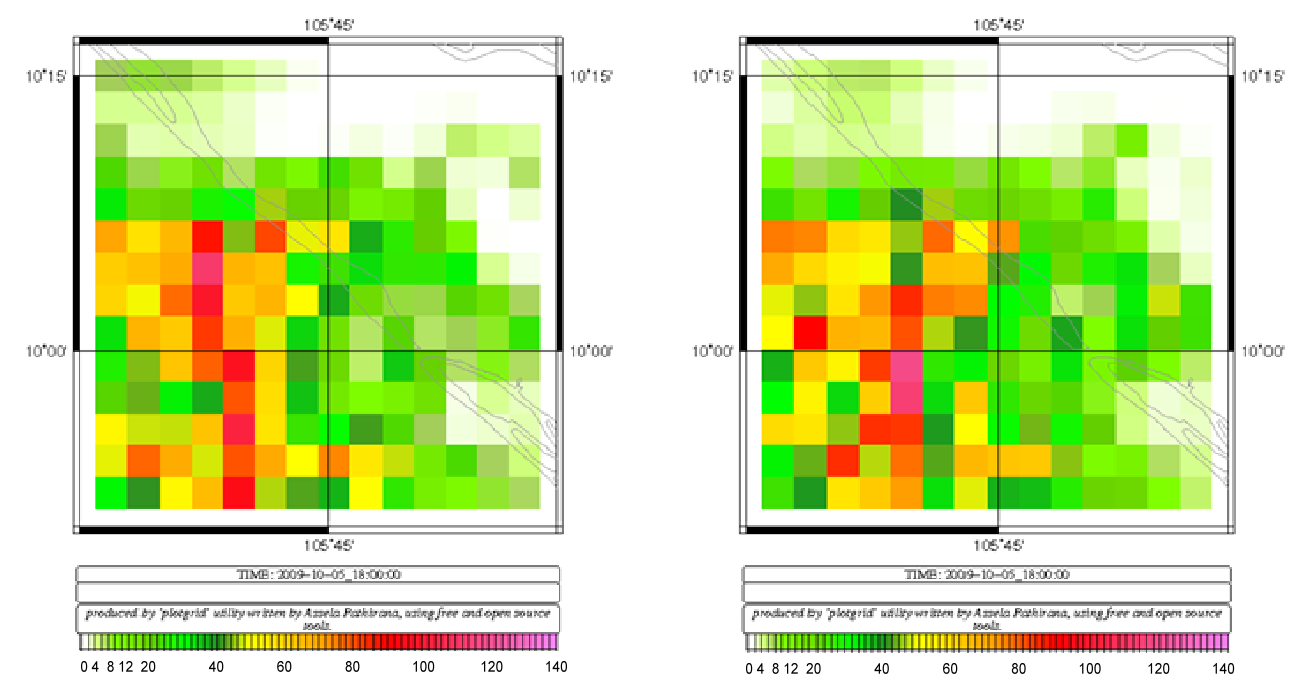

Past

Future

Fig. 12. Total rainfall simulated during the 5-6 October 2009 rainfall event for "Past" and "Future" land use. 

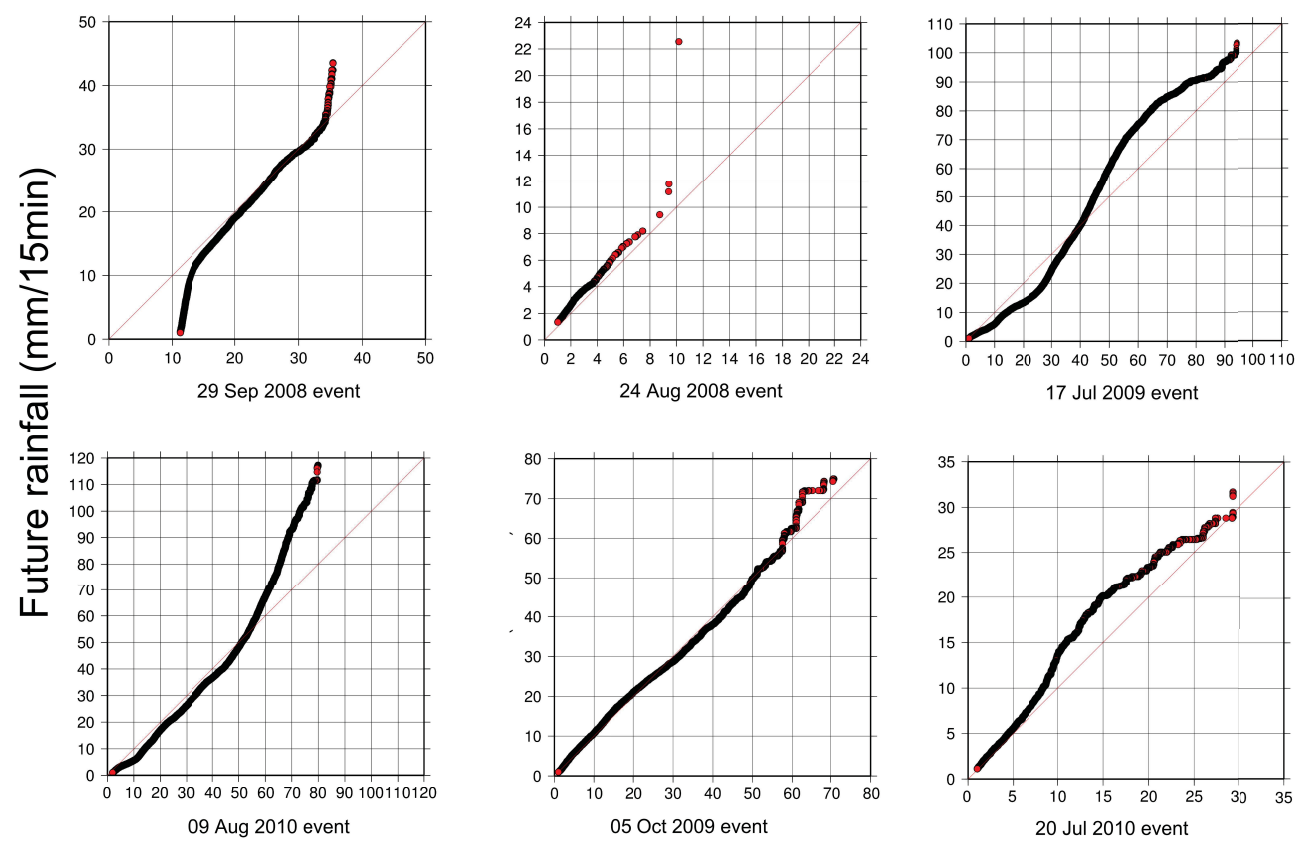

Past rainfall $(\mathrm{mm} / 15 \mathrm{~min})$

Fig. 13. Comparison of 15 min rainfall intensities for "Past" and "Future" scenarios for various historical events.

$100 \mathrm{~cm}$, and (iv) sea level rise of $100 \mathrm{~cm}$ combined with an increase of river runoff for high emission scenario (A1F1). Each of these climate scenarios was combined with two local scenarios (a) current land use and (b) future land use (2050), resulting in eight combined scenarios.

Figure 14 shows sample inundation results for four of the scenarios. The results of all eight are summarized in Fig. 15.

\section{Discussion and conclusions}

We conducted a detailed modeling study on the urban water system of Can Tho city in order to understand the impacts of future change on the already serious urban flooding situation of the city. Where possible, we used external resources to establish the future change, for example due to global climate change (sea level rise and changes in Mekong river flow). However, for local changes that are also important, there were no reliable external sources so we resorted to model simulations. First we employed an urban growth model to simulate future changes in land use driven by urbanization, and then a specially set-up, limited-area atmospheric-land surface model to estimate the changes in the local extreme rainfall due to land use change. Finally, we applied a dynamic 1-D/2-D coupled urban flood model on a selected neighbourhood to simulate the combined effects of sea level rise, upstream flow of Mekong, the local changes of rainfall, and hydrological changes due to urbanization on the already serious problem of urban flooding in Can Tho.

\subsection{Results}

The results show that (Fig. 15), in case the city develops in a "business as usual" scenario, the maximum inundation depth in the analysed area for a rainfall event like October 2009 will increase by $21 \%$ (about $18 \mathrm{~cm}$ ) by 2050 , solely due to the land use change-driven hydrological and hydrometeorological effects (i-b). The inundated area will increase by $18 \%$. The impact of climate change, in its worst combination (A1F1 flow with SLR $100 \mathrm{~cm}$ - scenario iva) on inundation depth is much more serious than that of urbanization-driven land use change. The maximum inundation depth in Can Tho may increase by more than $50 \mathrm{~cm}$ (around $60 \%$ ) in (iv-a). However, the inundated area is more sensitive to urbanization-driven hydrological and meteorological changes (scenario i-b versus ii-a, iii-a and iv-a).

In (iv-b), the scenario that combines climate impact with urban growth, the maximum inundation depth will increase to $1.51 \mathrm{~m}-$ an $80 \%$ increase. The most seriously inundated area is the area surrounding the intersection of Nguyen Van $\mathrm{Cu}$ and Mau Than Streets, close to Can Tho Medical College (Fig. 16a), all of which are located near the Ngong Channel, the main receiving canal of the district. When heavy rain occurs, the water from other roads, canals and sewers will converge into this canal. As the drainage capacity of the channel is not sufficient for this large quantity of water, the lowlying surrounding areas are routinely inundated. The possibility of the increase of inundation depth in this area up to $1.51 \mathrm{~m}$ is alarming indeed, as this level may pose a danger to human life. 

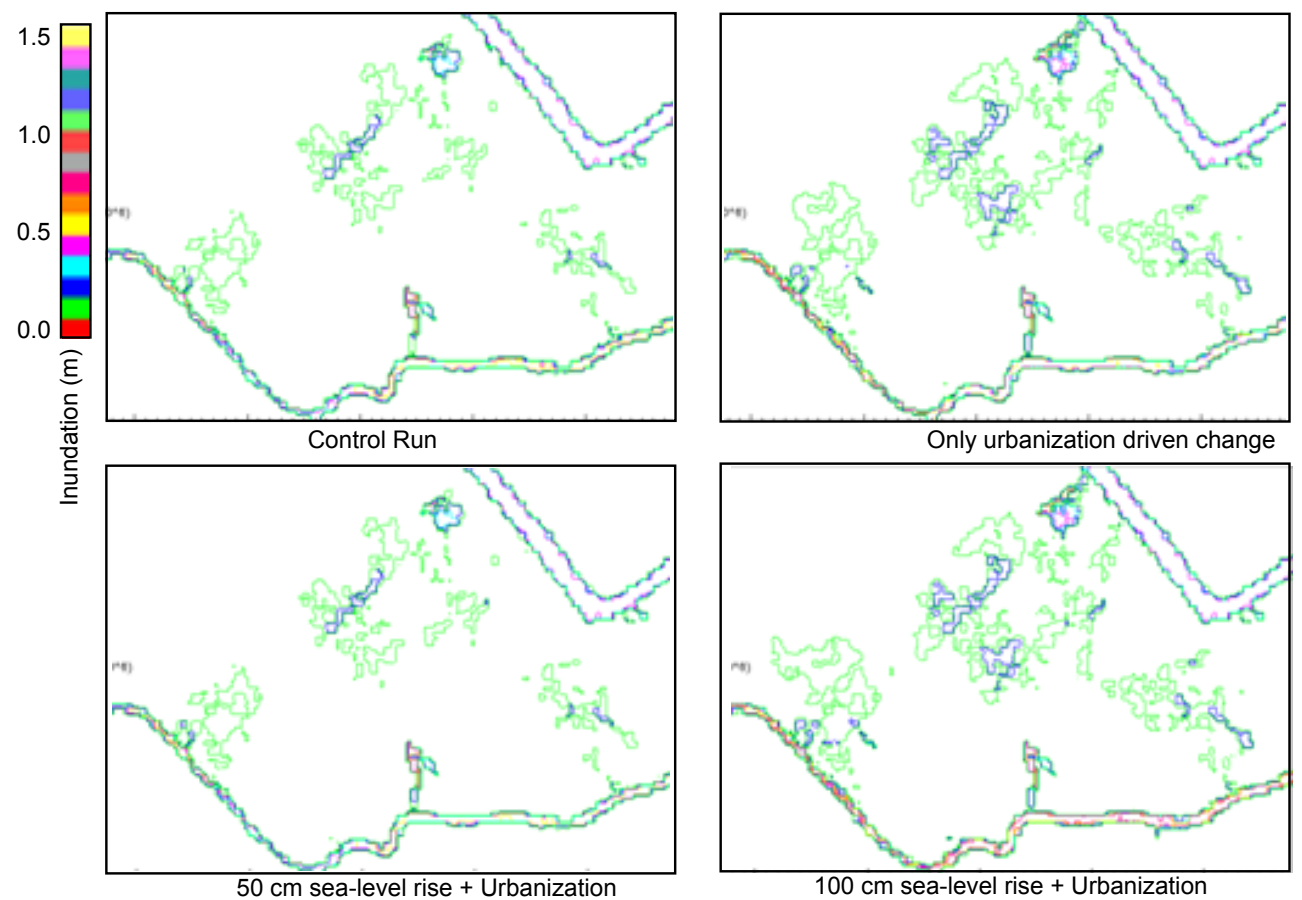

Fig. 14. Simulated inundation maps for selected scenarios (for October 2009 event; at 15:30 UTC, 5 October 2009).

Besides the above critical area, the maximum inundation depth of the rest of the areas do not change significantly. When these critical areas are neglected, this value is only $0.73 \mathrm{~m}$ in the scenario of A1F1 + SLR $100 \mathrm{~cm}$ compared to $0.66 \mathrm{~m}$ in the baseline scenario, which is located near Nguyen Thi Minh Khai, Phan Dinh Phung street. Detailed analysis showed that these areas' inundation depth is more sensitive to land use driven changes than to the impacts of the river water level.

Both in the present and the future, the area with high inundation depths $(>0.5 \mathrm{~m})$ is not excessively large. The maximum area of inundation depth $>0.5 \mathrm{~m}$ increased to only 26 ha (accounting for $12 \%$ of the total inundated area). The area increased by $20 \%$ due to urbanization-driven land use change (local hydro-meteorological and hydrological change) (i-b) and $34 \%$ due to climate change impacts on riverine flooding (iv-a). The combination of these two facts increase it by $50 \%$. It is interesting to note that while the total inundated area was more sensitive to urbanization impact on local precipitation, the "significantly" inundated area is much more affected by climate change impact on the riverine flooding.

\subsection{Sensitivity of drivers}

Investigation of the flooded areas shows two distinct categories of flooding, namely: (i) the areas dominated largely by local rainfall-driven flooding (Nguyen Thi Minh Khai, Phan Dinh Phung streets), and (ii) those influenced mainly by river water level. The area with highest flood levels (location (a) in
Fig. 16) is close to a major branch canal and hence directly influenced by the river level much more significantly. This is the reason for its high sensitivity for the climate drivers (for which we used river level as proxy). However, the relative insensitivity of the river level to the total inundated area shows that the influence of the river at the levels we have considered is not felt by the entire modelled area. The influence is very much localized to the neighbourhood of canals.

The area with second largest flood depth (location $b$ in Fig. 16) is much more influenced by urbanization impact (our proxies for this were local rainfall change due to urbanization and the change in hydrologic properties), though there is a significant impact of the climate change as well.

Another interesting feature of the impact of the river level is that it seems to have a certain tipping-point value - an increase of $50 \mathrm{~cm}$ alone (ii-a) does not have any influence on the inundation depth as compared to $100 \mathrm{~cm}$. On the other hand, a $50 \mathrm{~cm}$ increase combined with urbanization effect (ii-b) has non-negligible increase of maximum flood height compared to urbanization only. These complex interactions deserve future investigations.

\subsection{Limitations}

The goal of the present study was ambitious. The results obtained should be interpreted with the necessary attention to the limitations of the methodology and uncertainty inherent to complex modeling tasks.

First of all, by no means have we considered nearly all of the major influences of a changing environment. Climate 


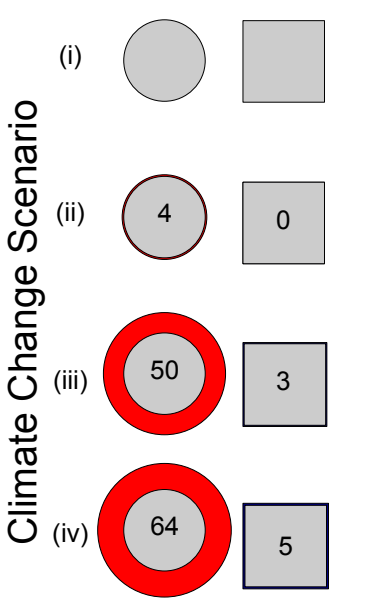

(a)

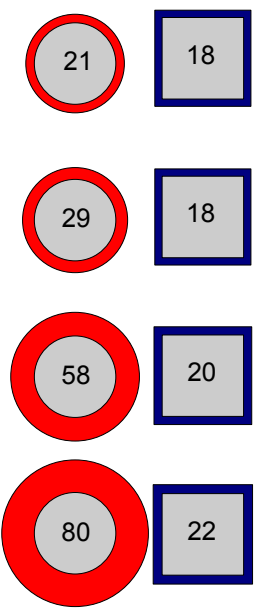

(b)

\section{Urbanization Scenario}

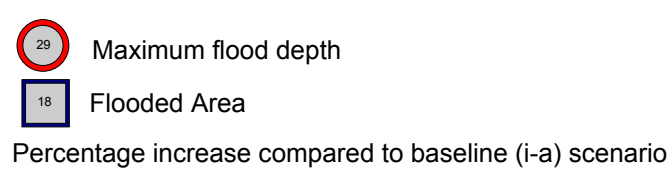

Fig. 15. The maximum inundation height and area of inundation for the eight scenarios. (a) No urbanization effect, (b) with urbanization effects; (i) current climate situation, (ii) sea level rise of $50 \mathrm{~cm}$, (iii) sea level rise of $100 \mathrm{~cm}$, and (iv) sea level rise of $100 \mathrm{~cm}$ combined with increase of river runoff for high emission scenario (A1F1). The maximum inundation depth and area for the baseline case was $0.84 \mathrm{~m}$ and $177 \mathrm{ha}$, respectively.

change does not only influence the river levels, though for the case of Can Tho, this remains a major connection. It will influence the nature and magnitude of extreme rainfall events. How this influence will interact with the urbanization-lead rainfall remains to be studied.

The drainage model we have constructed was quite accurate in terms of locations, structure and dimensions, as this was based on the construction plans obtained from the city authorities. However, there are a host of parameters that had to be estimated largely based on judgement. Examples are various catchment parameters, roughness values of pipes and exact operation of pumping stations. However, all of these parameters were kept constant between different scenarios, and therefore have not influenced the comparative results. Nevertheless, there are factors that could definitely change with time. For example, there are locations of the drains that are severely blocked due to sedimentation and solid waste at the moment. This situation could improve or become aggravated in the future, depending on the policies of the city and the behaviour of its population. These dynamics were ignored.

Perhaps the most significant assumption we made was that the growth of the city follows the historical growth patterns ("business as usual" assumption). In reality, it could deviate

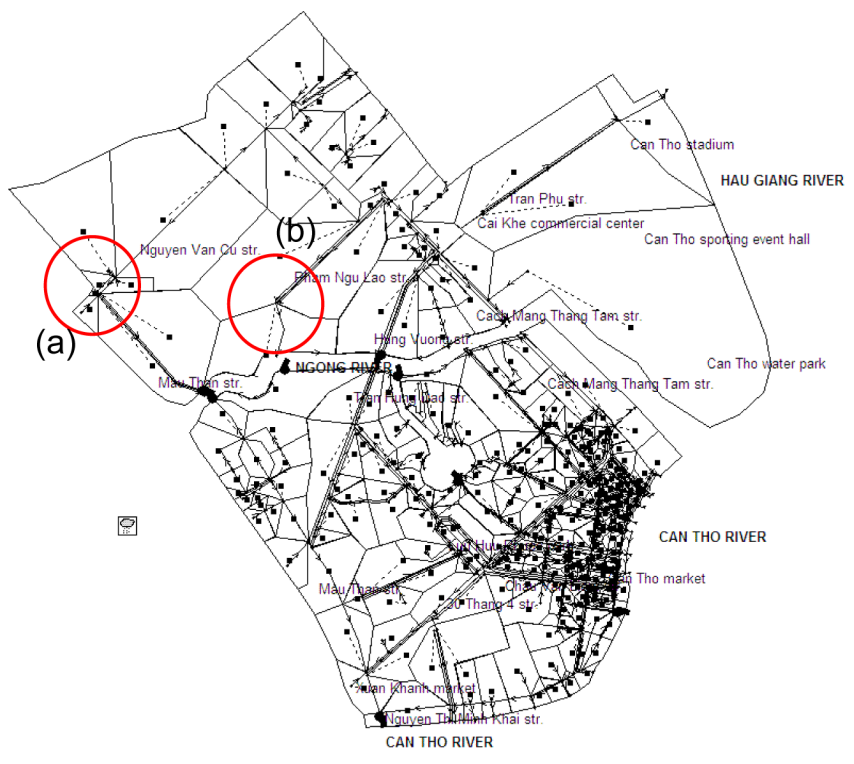

Fig. 16. Highly inundated areas. (a) Intersection of Nguyen Van $\mathrm{Cu}$ and Mau Than Streets. (b) Intersection of Nguyen Thi Minh Khai and Phan Dinh Phung streets.

from that significantly. On the one hand, enlightened city authorities may control the urban densities and might intervene in ways that could alleviate microclimatic impacts (e.g. introducing green areas). On the other hand, various new factors (e.g. new, faster means of transport from Ho Chi Minh city) could even accelerate the growth rate in the future.

We limited our analysis at the level of maximum flood depth and flooded area. However, for the policymaker the flood damage is a much more tangible parameter for comparison. We made a deliberate decision not to include this additional step in analysis due to large uncertainties involved in applying the process to Can Tho.

\section{Conclusions}

The present study is an attempt to integrate the impacts of both external and internal drives of future change of the urban flooding system. The external forcing due to climate change was considered by the river level increase due to the combined effect of sea level rise and anticipated increase of flow in the Mekong river. The urban growth was modeled by a land use simulator and the resulting changes in urban microclimate and hydrological system was used as in-ternal forcing.

We found that currently there are two types of areas with significant flood hazard, namely those locations predominantly impacted by the river level (e.g. Nguyen Van $\mathrm{Cu}$ and Mau Than Streets) and those affected by local heavy rainfall (Nguyen Thi Minh Khai, Phan Dinh Phung streets). In future scenarios the flooding situation in these locations will become worse. For example, for the combined (worst case) 
scenario of $100 \mathrm{~cm}$ sea level rise, increase of flow in Mekong and local change due to urbanization (scenario iv-b), the maximum inundation depth can reach $1.51 \mathrm{~m}$ (and $80 \%$ increase). Such a change clearly could transform the flooding in Can Tho city from a (significant) nuisance to a catastrophic disaster.

Another important point is the observed rainfall in the 2009 event, while high, is by no means exceptional. Statistical analysis of historical rainfall shows that the maximum hourly rainfall of Can Tho has exceeded $50 \mathrm{~mm}$ during the period of $25 \mathrm{yr}$ from 1978 to 2003 . The total rainfall during hours 15 and $16(80 \mathrm{~mm})$ has a return period of about 5 yr. However, the coincidence of high river level and extreme rainfall (compare timing in Figs. 7 and 8) was a much more infrequent occurrence. However, it is likely that Can Tho will continue to experience flood events of similar or higher magnitude.

One of the unique features of this study that sets it apart from typical comparable climate/future change impact studies, is the attempt made to cover both internal pressures on the urban system and external ones by a matrix of scenarios. Particularly the consideration of the impact of urbanization on urban rainfall intensities, which could be significant as shown by the results, is an important feature.

Due to the ambitious goal above, the current study involves a complex chain of analysis. Such analyses invariably generate a significant degree of uncertainty in the final outcome. We urge the reader to exercise caution when interpreting the results presented here in a quantitative sense. However, we believe that the relative changes indicated could be useful, given that the uncertainties do not change significantly between "past" (baseline) scenario's and "future" scenario's modeling.

Each stage of simulations has its own sources of significant uncertainties: urbanization modeling was largely based on rules derived from past behaviour of the city. While this would capture the essential behaviour of the urbanization as conditioned by geographical, cultural and societal factors - there are a host of other parameters that will not remain unchanged in the future. For example a major trunk road is being constructed between Can Tho and Ho Chi Minh city, which would make travel between the two cities much faster. This will definitely have a hitherto unseen influence on growth. On the other hand, the government of Vietnam is very active in planning for the future, taking climate change and other future changes into account. Future regulatory action can restrict urban growth.

In the case of urban heat island-driven rainfall simulation, we have considered only several past rainfall events due to practical limitations of computational expense. This definitely leads to a large degree of uncertainties in the results. Finally, the urban flood model was calibrated using only a limited set of reported flood depths. Presently there is no way to do a systematic calibration of the 1-D and 2-D components of the model and their integration due to complete lack of ob- served data. While this is a common situation in urban flood studies, it should nevertheless be taken into account when interpreting the presented results.

Perhaps the best way to interpret results of the current study is to look at them as a set of "what-if" scenarios without a specific timeline attached. For example, comparing scenario (i-a) with (iii-b) gives an idea of the relative increase of flood hazard due to the combined effect of a mean sea level rise of $50 \mathrm{~cm}$ and significant increase of urbanization of Can Tho city. In order to provide more concrete estimates, the joint probabilities of these events happening together should be computed, e.g., for (iv-b), what is the probability of tidal peak coinciding with the peak pluvial runoff from a 2009like event, and that of the flow in Mekong being at its seasonal peak. With the current level of data availability, such analysis will hardly be fruitful.

The indications are that the combined influence of climate change and urban growth on the urban flooding situation is significant indeed. However, the starting point of the solution is not only related to the distant future, but has very much to do with the present situation: The city does not have a suitable urban drainage system and adequate flood protection. All remedial action should probably start at this point. However, the fact that a majority of the area of the city does not have a drainage system provides a wonderful opportunity future planning. When the new systems are designed, it is extremely important to consider the anticipated changes in the future: not only due to climate change, but also due to the impacts (hydrologic and hydrometeorological) of urban growth. These demand innovative designs that combine both traditional solutions (implementing and upgrading the drainage system and flood defences and non-standard (e.g. sustainable urban drainage, resilient buildings) approaches. This is an extremely important area for future research.

In the current study we limited the hydraulic modeling domain to the urban system, using river level as boundary condition for the model. Therefore we did not have control over the simulation of hydrodynamics along the Mekong river. Inevitably, this fact limits our abilities to test various sea level and river-flow scenarios for which published data is not available.

The presented study focuses on flood hazard. To have a complete picture of flood risk, the probabilities of occurrence have to be quantified and a flood vulnerability assessment needs to be carried out, which may involve analysing socialeconomic issues. This was beyond the scope of this study.

Acknowledgements. This study was funded as a part of the PRoACC (Post-doctoral Programme on Climate change Adaptation in the Mekong River Basin) programme by the Netherlands Ministry of Development Cooperation (DGIS) through the UNESCO-IHE Partnership Research Fund. It was carried out jointly with UNESCO-IHE and Vietnam Institute of Meteorology, Hydrology and Environment. It has not been subjected to peer and/or 
policy review by DGIS or UNESCO-IHE, and, therefore, does not necessarily reflect the views of these institutions.

We would like to thank Heiko Apel who reviewed the manuscript and suggested a number of significant ways to improve the final paper.

Edited by: D. Solomatine

\section{References}

ActionAid: Climate change, urban flooding and the rights of the urban poor in Africa, 2006.

Aikawa, M., Hiraki, T., and Eiho, J.: Change of atmospheric condition in an urbanized area of Japan from the viewpoint of rainfall intensity, Environ. Monitor. Assess., 148, 449-453, doi:10.1007/s10661-008-0174-0, 2008.

Begnudelli, L. and Sanders, B. F.: Unstructured grid Finite-Volume Algorithm for Shallow-Water Flow and Scalar Transport with Welting and Drying, J. Hydraul. Eng., 132, 371-384, 2006

Delelegn, S. W., Pathirana, A., Gersonius, B., Adeogun, A. G., and Vairavamoorthy, K.: Multi-objective optimisation of cost-benefit of urban flood management using a 1D2D coupled model, Water Sci. Technol., 63, 1054-1060, doi:10.2166/wst.2011.290, 2011.

Delgado, J. M., Apel, H., and Merz, B.: Flood trends and variability in the Mekong river, Hydrol. Earth Syst. Sci., 14, 407-418, doi:10.5194/hess-14-407-2010, 2010.

EPA: Storm Water Management Model (SWMM), online, Updated 8 June 2010, available at: http://www.epa.gov/nrmrl/wswrd/wq/ models/swmm/ (last access: 12 February 2011), 2010.

IMHEN - Vietnam Institute of Meteorology, Hydrology and Environment: Impacts of Climate Change on Water Resources and Adaptation Measures, 2010.

IPCC: Climate change and Biodiversity, Intergovernmental Panel on Climate change, Technical Paper - V, 2002.

IPCC: Climate change 2007: Synthesis Report - An Assessment of the Intergovernment Panel on Climate change, 2007.

Kingston, D. G., Thompson, J. R., and Kite, G.: Uncertainty in climate change projections of discharge for the Mekong River Basin, Hydrol. Earth Syst. Sci., 15, 1459-1471, doi:10.5194/hess-15-1459-2011, 2011.

Mas, J. F., Pérez Vega, A., and Clarke, K.: Assessing "spatially explicit" land use/cover change models, Forest Landscapes and Global Change-New Frontiers in Management, Conservation and Restoration, Proceedings of the IUFRO Landscape Ecology Working Group International Conference, 21-27 September 2010, Bragança, Portugal, 2010.

Milly, P. C. D., Betancourt, J., Falkenmark, M., Hirsch, R. M., Kundzewicz, Z. W., Lettenmaier, D. P., and Stouffer, R. J.: Stationarity Is Dead: Whither Water Management?, Science, 319, 573-574, doi:10.1126/science.1151915, 2008.

Mitchell, K.: The community NOAH-LSM - User's guide public release version 2.7.1, available at: ftp://ftp.emc.ncep.noaa.gov/ mmb/gcp/ldas/noahlsm/ver_2.7.1 (last access: 22 May 2011), 2005.

MONRE: Climate change and sea level rise scenarios for Vietnam, Ministry of Natural Resources and Environment, Hanoi, Vietnam, 2009a.

MONRE: Detailed plan of Can Tho City sewer system: The basic solution to prevent flooding, online, updated: 24 February 2009, available at: http://monre.gov.vn (last access: 12 August 2010), 2009b.

Mote, T. L., Lacke, M. C., and Shepherd, J. M.: Radar signatures of the urban effect on precipitaton distribution: A case stuty for Atlanta, Georgia, Geophys. Res. Lett., 34, L20710, doi:10.1029/2007GL031903, 2007.

National Hydro-meteorological Service: Overview of historical flood in 2000 in Mekong River Delta, online, updated 6 September 2010, available at: http://www.nchmf.gov.vn (last access: 10 April 2011), 2010a.

National Hydro-meteorological Service: Overview of special high flood in 2001 in Mekong River Delta, online, updated 6 September 2010, available at: http://www.nchmf.gov.vn (last access: 10 April 2011), 2010b.

NIURP (National Institute for Urban and Rural Planning) : Under Vietnam Ministry of Construction, 2010, Development Strategies (CDS) for Medium-Size Cities in Vietnam: Can Tho and Ha Long, 2010.

Pathirana, A., Maheng Dikman, M., and Brdjanovic, D.: A Twodimensional pollutant transport model for sewer overflow impact simulation, in: Proceedings: 12th International Conference on Urban Drainage, Porto Alegre/Brazil, 10-15 September, 2011.

Pathirana, A., Veerbek, W., Denekew, H., and Banda, A. T.: Urban Growth, Heat Islands and Extreme Rainfall: A Modelling Experiment, Atmos. Res., in review, 2013.

Seto, K. C. and Kaufmann, R. K.: Urban Grounth in South China and Impacts on Local Precipitation, Fifth Urban Research Symposium, 2009.

Shepherd, J. M., Pierce, H., and Negri, A. J.: Rainfall modification by major urban areas: Observations from spaceborne rain radar on the TRMM satellite, J. Appl. Meteorol., 41, 689-701, 2002.

Tewari, M. F., Chen, F., Kusaka, H., and Miao, S.: Coupled WRF/Unified Noah/urban-canopy modeling system, NCAR WRF Documentation, NCAR, Boulder, 1-20, 2008.

Tran Van Tu (chairman of the Social Sciences and Humanities Can Tho): Status of some coastal areas related to climate change adaptation and sustainable development of Cuu Long River Delta (MRD), 2010.

UN: World Urbanization Prospectus: The 2001 Revision, ESA/P/WP.173, 2001.

UN: World Urbanization Prospects: The 2005 Revision, ESA/P/WP/200, 2006.

UNFCCC: Climate change, small island developing States, 2005.

Verbeek, W., Denekew, H. B., Pathirana, A., Brdjanovic, D., Zevenbergen, C., and Bacchin, T. K.: Urban Growth Modeling to Predict the Changes in the Urban Microclimate and Urban Water Cycle, 12th International Conference on Urban Drainage, Brazil, 2011.

Vietbao (Vietnam News to the world): Can Tho: Cai Son continues to serious subsidence, online, updated: 14 April 2006, available at: http://vietbao.vn/Xa-hoi (last access: 10 September 2010), 2006.

WMO/GWP Associate Program on Flood Management: Urban Flood Risk Management - A tool for Integrated Flood Management, 2008.

Youth online: Historical inundation in Can Tho city, online, updated: 5 October 2009, available at: http://tuoitre.vn (last access: 12 May 2010), 2009. 